\title{
Research on structural strength of asphalt carrier related to the effect of temperature field
}

\author{
Chen Di-yi ${ }^{1, a}$, Wang Wei ${ }^{2, b}$, Xie Yong-he ${ }^{3, c}$ and Xu Tian-qi ${ }^{4, d}$ \\ 1,2,3,4 School of Naval Architecture and Ocean Engineering; Zhejiang Ocean University; Zhejiang \\ Zhoushan 316022; China \\ a1576893208@qq.com, b147298485@qq.com, '104308275@qq.com, d810677423@qq.com
}

\begin{abstract}
Keywords: Asphalt carrier; Thermal stress field; Finite element; Structural strength Abstract. The 6600 DWT asphalt carrier is taken as an example, utilizing the finite element software MSC/PATRAN and MSC/NASTRAN, which the research on yield and bucking direct calculation of asphalt carrier structural strength is conducted respectively dealing with temperature field and without temperature field. The influence of temperature field on asphalt carrier's structural strength is analyzed and reasonable intensive scheme is proposed against structures dissatisfied the requirement of strength, which provide important reference to the design and construction of similar ships.
\end{abstract}

\section{Introduction}

With the development of modernizing, highway construction is increasing day by day and the demand for petroleum asphalt is also adding more and more, which asphalt carrier is playing a great role in the transportation of asphalt ${ }^{[1]}$. Asphalt carrier is a ship designed to transport high temperature molten liquid petroleum asphalt, which the temperature of cargo is normally controlled between $120 \sim 180{ }^{\circ} \mathrm{C}^{[23]}$.

The liquid cargo cabin of the asphalt carrier is divided into two types, which are independent and integral. More and more ship-owners are fascinated by asphalt carrier. The advantages of integral liquid asphalt carrier are high utilization ratio of cargo cabin and easy to clean ${ }^{[4]}$. Owing to the high temperature of liquid asphalt in integral liquid cargo carrier and hull structure, in addition, the yield strength of the steel decreases with the increase of temperature, high temperature liquid cargo is likely to endanger the safety of the structure ${ }^{[56}$. Therefore, thermal stress analysis of asphalt carrier is necessary.

In this paper, the direct calculation of asphalt carrier structural strength is conducted respectively dealing with temperature field ${ }^{[7]}$ and without temperature field, analyzing the influence of temperature field on asphalt carrier structural strength and proposing reasonable intensive scheme against structures dissatisfied the requirement of strength, which improves the rationality of structural design and provides reliable data sources for the optimization of cargo cabin structure and transformation work of asphalt carrier. It has very important significance.

\section{Generalization of asphalt carrier}

The topic origin of this paper is a 6600 DWT asphalt carrier whose liquid cargo cabin is integral, which the overall length is $113.6 \mathrm{~m}$, length between perpendiculars is $107.4 \mathrm{~m}$, molded breadth is $16.80 \mathrm{~m}$, molded depth is $8.80 \mathrm{~m}$, designed draft is $6.60 \mathrm{~m}$ and square coefficient is 0.7892 . The area of cargo oil cabin is double bottom and double broadside structure constructed by longitudinal bulkhead with 1 groove type, transverse bulkhead with 4 groove types separating into 10 cargo cabins except for strengthening structure of deck. The top, bottom and medial part of cargo cabin are made of rock wool insulation materials whose thickness is $100 \mathrm{~mm}$. Rock wool insulation materials are set up in different positions which the distance between transverse bulk head and boundary is respectively $900 \mathrm{~mm}, 1000 \mathrm{~mm}$ and $1100 \mathrm{~mm}$. CCSA grade steel is adopted in hull structure. 


\section{Direct finite element calculation}

The research on direct finite element calculation of asphalt carrier's structural strength related to the influence of temperature field is based on several premise hypotheses ${ }^{[8]}$. The heat transferring calculation is based on an assumed steady state heat transferring in three-dimensional space, no change of material parameters and boundary conditions is made in conjunction with any temperature change in the analysis of linear heat transferring, and only the effects of transferring through structures and insulation are considered.

The thermal calculation in this Section is based on the assumption of a "sequentially coupled heat-structure (sequentially coupled problem)", i.e., the effects of changes in the temperature field on the machinery field is considered without taking account of the effects of the latter on the former. Moreover, the high temperature creeping effects of structures are not considered.

In calculation, it is assumed that heat is transferred between hull structural members by conduction, and that heat exchange between air and hull structural members exposed to it is natural convection only.

\section{Finite element models of cabin}

Numerical simulation analysis is based on relevant design construction drawings of 6600 DWT asphalt carrier, utilized by finite element software MSC/PATRAN and MSC/NASTRAN.

Basing on "RULES FOR CLASSIFICATION OF SEA-GOING STEEL SHIPS" in CCS, the research on strength direct calculation of asphalt carrier's main components is conducted by finite element models ${ }^{[8]}$. The range of cabin model is three cargo cabins in close to area of cargo cabin in mid-ship, which longitudinal range is from Fr49 to Fr113 and vertical range is the whole molded depth. Rock wool material of cargo cabin is modeled by three dimension element and the rest of other ship components are modeled by plate and beam element. Coordinate system is used in right hand coordinate system and the origin is located at bottom midline of Fr49, which the bow is positive direction of $\mathrm{X}$ axis, the portside is positive direction of $\mathrm{Y}$ axis and topside of $\mathrm{Z}$ axis is positive direction. The finite element models are shown in Figure 1, and Figure 2 demonstrates the rock wool insulation layer models conducted by solid element. Material properties of steel and required calculating parameters of temperature field are shown in Table 1.

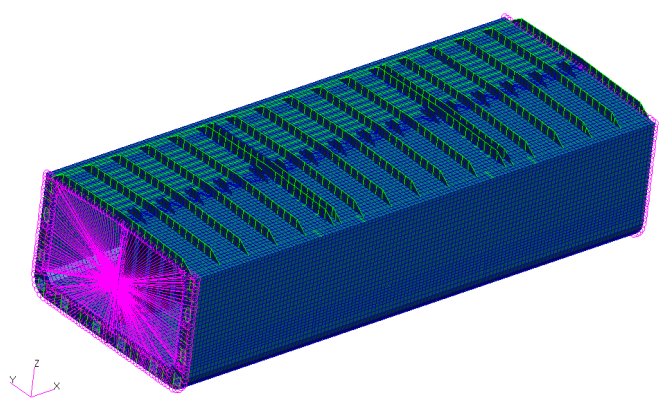

Fig. 1 Finite element model of cabin

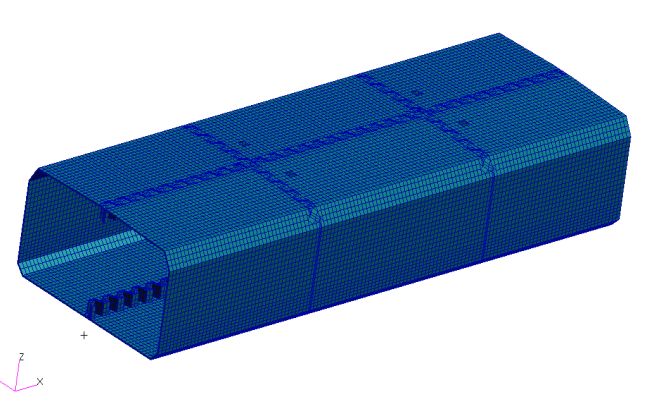

Fig. 2 Rock wool insulation layer models Tab.1 Material properties and parameters of temperature field

\begin{tabular}{|c|c|c|c|}
\hline Category & Parameter value & Category & Parameter value \\
\hline Elastic modulus of steel & $2.06 \times 10^{5} \mathrm{~N} / \mathrm{mm}^{2}$ & $\begin{array}{l}\text { Heat transfer coefficient of } \\
\text { rock wool }\end{array}$ & $0.046 \mathrm{~W} /\left(\mathrm{m} \cdot{ }^{\circ} \mathrm{C}\right)$ \\
\hline Poisson ratio of steel & 0.3 & $\begin{array}{l}\text { Thermal expansion } \\
\text { coefficient of steel }\end{array}$ & $1.1 \times 10^{-5} /{ }^{\circ} \mathrm{C}$ \\
\hline $\begin{array}{l}\text { Material density of steel } \\
\text { Heat transfer coefficient of steel }\end{array}$ & $\begin{array}{c}7.85 \mathrm{t} / \mathrm{m}^{3} \\
60.6 \mathrm{~W} /\left(\mathrm{m} \cdot{ }^{\circ} \mathrm{C}\right)\end{array}$ & $\begin{array}{l}\text { Convection coefficient of air } \\
\text { and plate in ballast tank }\end{array}$ & $11.6 \mathrm{~W} /\left(\mathrm{m}^{2} \cdot{ }^{\circ} \mathrm{C}\right)$ \\
\hline
\end{tabular}

\section{Boundary conditions}

Basing on the requirements of "RULES FOR CLASSIFICATION OF SEA-GOING STEEL SHIPS", boundary condition refers to double hull oil tankers ${ }^{[8]}$. An independent point $\mathrm{H}$ is to set in way of intersection of the neutral axis with the longitudinal centerline section without end planes A and B, the longitudinal bending moment is to be applied on the point $\mathrm{H}$, and the degrees of freedom $\delta_{x}, \delta_{y}$ and $\delta_{z}$ of each member node for end planes is linked to the independent point. The constrain condition 
of independent points at both ends are shown in Tab.2. Boundary condition for local loads is shown in Tab.3.

Tab.2 Boundary condition for global load

\begin{tabular}{|c|c|c|c|c|c|c|}
\hline \multirow{2}{*}{ Position } & \multicolumn{3}{|c|}{ Displacement constrain } & \multicolumn{3}{|c|}{ Rotation constrain } \\
\hline & $\delta_{x}$ & $\delta_{y}$ & $\delta_{z}$ & $\theta_{x}$ & $\boldsymbol{\theta}_{y}$ & $\theta_{z}$ \\
\hline End planes A,B & Link & Link & Link & - & $\longrightarrow$ & 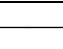 \\
\hline $\begin{array}{l}\text { Independent point } \mathrm{H} \\
\text { (end plate } \mathrm{A})\end{array}$ & Constraint & Constraint & Constraint & Constraint & BM. & \\
\hline $\begin{array}{l}\text { Independent point } \\
\text { (end plate B) }\end{array}$ & & Constraint & Constraint & Constraint & BM. & \\
\hline $\begin{array}{c}\text { Node } G \\
\text { (full-breadth model) }\end{array}$ & & Constraint & & & & \\
\hline
\end{tabular}

Tab3 Boundary condition for local loads

\begin{tabular}{|c|c|c|c|c|c|c|}
\hline \multirow{2}{*}{ Position } & \multicolumn{3}{|c|}{ Displacement constrain } & \multicolumn{3}{|c|}{ Rotation constrain } \\
\hline & $\delta_{x}$ & $\delta_{y}$ & $\delta_{z}$ & $\theta_{x}$ & $\theta_{y}$ & $\theta_{r}$ \\
\hline End planes A,B & Constraint & - & - & - & Constraint & Constraint \\
\hline Intersection $\mathrm{C}$ & - & - & spring & - & - & - \\
\hline Node G & & Constraint & & & & \\
\hline ( full-breadth model) & & Consulant & & & & \\
\hline
\end{tabular}

Note: BM-Bending Moment; The position of the node $\mathrm{G}$ is the intersection of the longitudinal section of the bulkhead at the front and back of the middle of the cargo hold and the bottom of the ship.

\section{Calculating loading condition}

\section{Loading condition of asphalt carrier}

In accordance with the requirements of the "standard" ${ }^{[8]}$, yield strength of this cargo cabin is calculated by finite element models. Loading conditions of the whole liquid cargo cabin of asphalt carrier shall take the following requirements: full load and half load in the above modes are taken into consideration with regard to (a), (b) and (c). Specific loading conditions are shown in Figure 3 to 5 , expressing horizontal, longitudinal section diagram. Load condition of temperature load is shown in Tab.4.

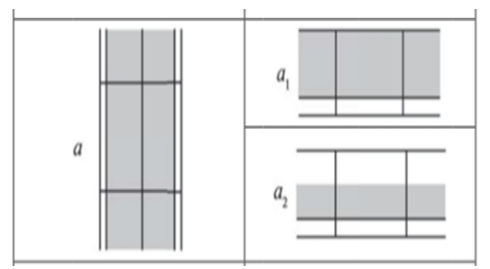

Fig.3 Load condition of (a)

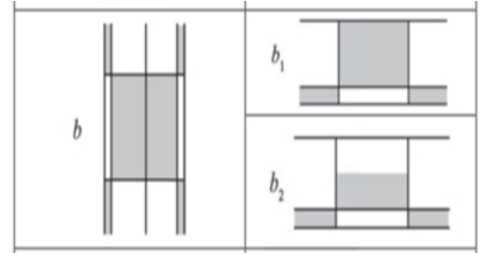

Fig.4 Load condition of (b)

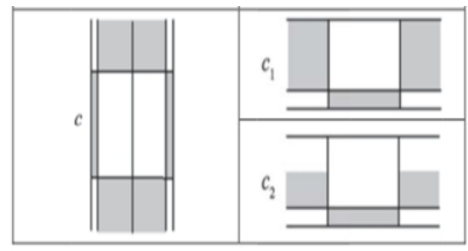

Fig.5 Load condition of (c)

Tab.4 Load condition of temperature load

\begin{tabular}{lcccccc}
\hline $\begin{array}{l}\text { Name of } \\
\text { temperature } \\
\text { Loading condition }\end{array}$ & $\begin{array}{c}\text { Loading } \\
\text { condition 1 }\end{array}$ & $\begin{array}{c}\text { Loading } \\
\text { condition 2 }\end{array}$ & $\begin{array}{c}\text { Loading } \\
\text { condition 3 }\end{array}$ & $\begin{array}{c}\text { Loading } \\
\text { condition 4 }\end{array}$ & $\begin{array}{c}\text { Loading } \\
\text { condition 5 }\end{array}$ & $\begin{array}{c}\text { Loading } \\
\text { condition 6 }\end{array}$ \\
\hline & LC-T-a1 & LC-T-a2 & LC-T-b1 & LC-T-b2 & LC-T-c1 & LC-T-c2 \\
\hline
\end{tabular}

\section{Loading condition for global and local load of asphalt carrier}

Local load is to deal with the temperature distribution and thermal stress calculation under the condition of full load and half load, which Loading condition c corresponds to the full load condition and loading condition b corresponds to the half load condition. Condition (a) only considers sagging and (b), (c) respectively considers sagging and hogging. Detailed Loading conditions are shown in Tab.5. 
Tab.5 Detailed table of the superposed loading condition

\begin{tabular}{cccc}
\hline $\begin{array}{c}\text { Serial number of } \\
\text { loading condition }\end{array}$ & $\begin{array}{c}\text { Loading condition of } \\
\text { global load }\end{array}$ & $\begin{array}{c}\text { Loading condition } \\
\text { of local load }\end{array}$ & $\begin{array}{c}\text { Loading condition of the combination } \\
\text { of global and local load }\end{array}$ \\
\hline Loading condition 1 & LC-abc-ZT-zhongchui & LC-a1-JUBU & Combine,zhongchui,a1 \\
Loading condition 2 & LC-abc-ZT-zhongchui & LC-a2-JUBU & Combine,zhongchui,a2 \\
Loading condition 3 & LC-abc-ZT-zhongchui & LC-b1-JUBU & Combine,zhongchui,b1 \\
Loading condition 4 & LC-abc-ZT-zhongchui & LC-b2-JUBU & Combine,zhongchui,b2 \\
Loading condition 5 & LC-bc-ZT-zhonggong & LC-b1-JUBU & Combine,zhonggong,b1 \\
Loading condition 6 & LC-bc-ZT-zhonggong & LC-b2-JUBU & Combine,zhonggong,b2 \\
Loading condition 7 & LC-abc-ZT-zhongchui & LC-c1-JUBU & Combine,zhongchui,c1 \\
Loading condition 8 & LC-abc-ZT-zhongchui & LC-c2-JUBU & Combine,zhongchui,c2 \\
Loading condition 9 & LC-bc-ZT-zhonggong & LC-c1-JUBU & Combine,zhonggong,c1 \\
Loading condition 10 & LC-abc-ZT-zhongchui & LC-c2-JUBU & Combine,zhonggong,c2 \\
\hline
\end{tabular}

Note: Corresponding temperature load is involved in local load.

\section{Calculation of loads}

Calculation of loads contain asphalt load, outboard water load, ballast water load, load caused by liquid cargo tank structure's temperature distribution and end bending moment. The value of three dimensional space temperature field distribution obtained in heat transfer analysis is made as the temperature load of thermodynamic calculation ${ }^{[9]}$. Temperature field is obtained basing on specific loading condition, which temperature distribution of specific temperature field is shown in Tab.6. The schematic diagram of temperature distribution under several temperature loading conditions is shown in Figure 6 to 7.

Tab.6 Temperature distribution

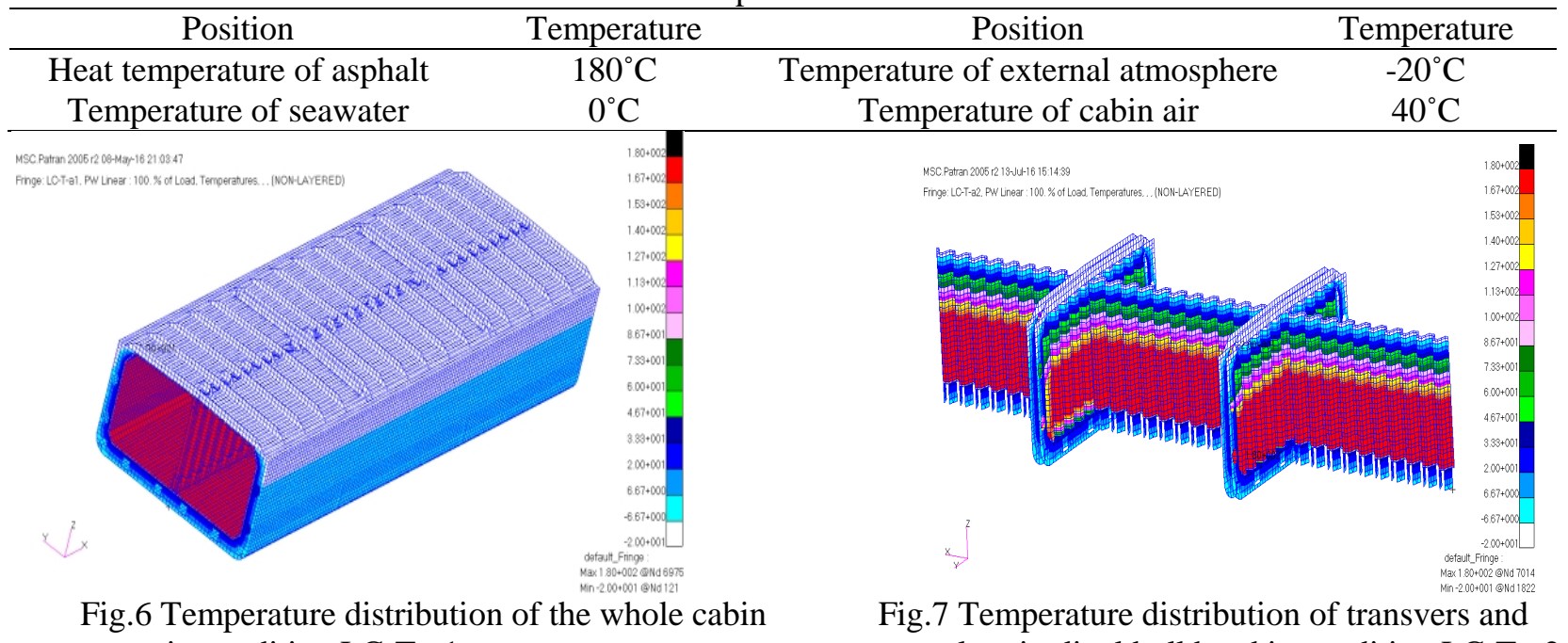
in condition LC-T-a1

longitudinal bulkhead in condition LC-T-a2

\section{Calculating result of hull structure strength}

Two calculating results are analyzed respectively dealing with temperature field and without temperature field in this paper and the influence of temperature on hull structure strength. Reasonable intensive scheme is proposed against structures dissatisfied the requirement of strength. Yield and bulking strength calculating results of hull components are obtained in two different conditions, which a cabin of amid ship is made as the range of bulking check. It is shown in Tab.7. The results of structural yield and plates' bulking dissatisfied the allowable requirements of strength are revealed in Fig.8 to 15. 
Tab.7 Comparison of the different hull structural strength results considering temperature and without temperature

\begin{tabular}{llccccc}
\hline \multicolumn{1}{c}{ Hull structure } & $\begin{array}{c}\text { Equivalent } \\
\text { stress without } \\
\text { temperatures } \\
\left(\mathrm{N} / \mathrm{mm}^{2}\right)\end{array}$ & $\begin{array}{c}\text { Equivalent } \\
\text { stress with } \\
\text { temperatures } \\
\left(\mathrm{N} / \mathrm{mm}^{2}\right)\end{array}$ & $\begin{array}{c}\text { Allowable } \\
\text { equivalent } \\
\text { stress } \\
\left(\mathrm{N} / \mathrm{mm}^{2}\right)\end{array}$ & $\begin{array}{c}\text { Buckling safety } \\
\text { equivalent value } \\
\text { without } \\
\text { temperature }\end{array}$ & $\begin{array}{c}\text { Buckling safety } \\
\text { equivalent value } \\
\text { with temperature }\end{array}$ & Criterion \\
\hline $\begin{array}{l}\text { Deck } \\
\text { Bottom shell plating }\end{array}$ & 138 & 243 & 220 & 0.858 & 0.444 & 0.8 \\
$\begin{array}{l}\text { Inner bottom plating } \\
\text { Side shell plating }\end{array}$ & 119 & 184 & 220 & 0.839 & 0.948 & 0.8 \\
$\begin{array}{l}\text { Inner shell plating } \\
\text { Sloping plating of }\end{array}$ & 191 & 235 & 220 & 1.53 & 0.516 & 0.8 \\
hopper tank & 130 & 217 & 220 & 1.44 & 1.41 & 0.8 \\
$\begin{array}{l}\text { Longitudinal } \\
\text { bulkhead }\end{array}$ & 161 & 210 & 220 & 0.893 & 0.886 & 0.8 \\
$\begin{array}{l}\text { Horizontal girder } \\
\text { in double hulls }\end{array}$ & 130 & 220 & 220 & 1.58 & 0.994 & 0.8 \\
$\begin{array}{l}\text { Bottom girder } \\
\begin{array}{l}\text { Double bottom floor } \\
\text { Transverse bulkhead }\end{array}\end{array}$ & 174 & 220 & 220 & 1.97 & 1.22 & 0.8 \\
$\begin{array}{l}\text { Transverse web frame } \\
\text { Sloping plating of }\end{array}$ & 114 & 306 & 235 & 1.35 & 0.893 & 1 \\
top side tank & 160 & 274 & 175 & 1.25 & 0.584 & 0.8 \\
\hline
\end{tabular}

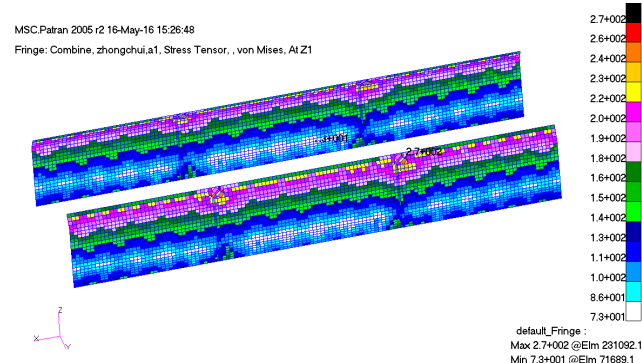

Fig.8 Equivalent stress distribution of side shell plating sloping plating of top side tank

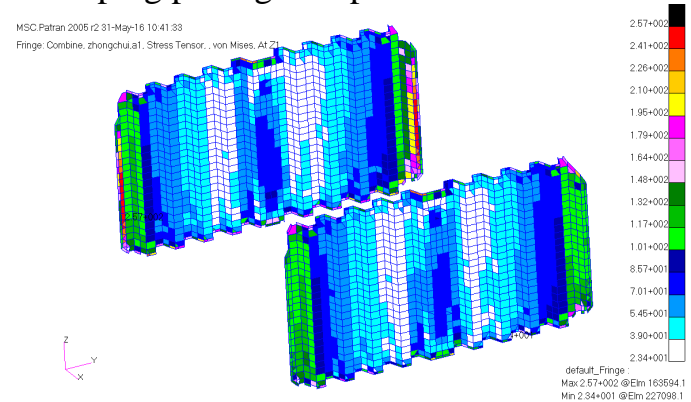

Fig.10 Equivalent stress distribution of transverse but

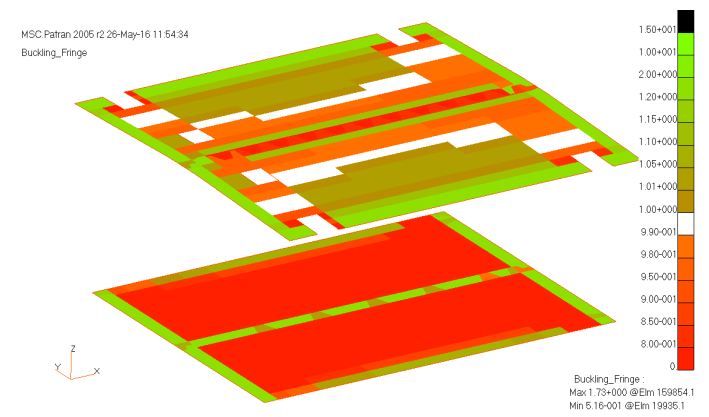

Fig.12 Buckling strength of deck and inner bottom

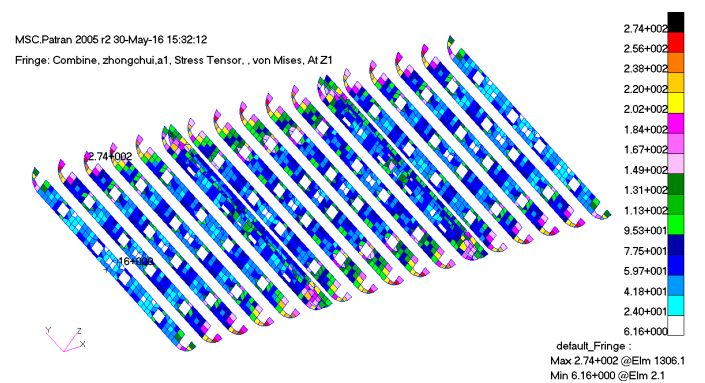

Fig.9 Equivalent stress distribution of double bottom and floor

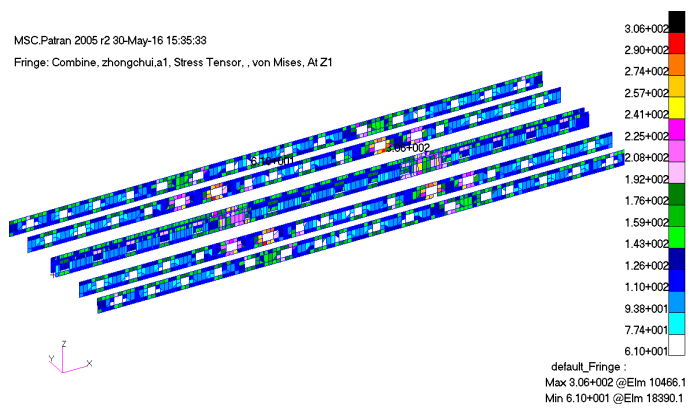

Fig.11 Equivalent stress distribution of bottom girder

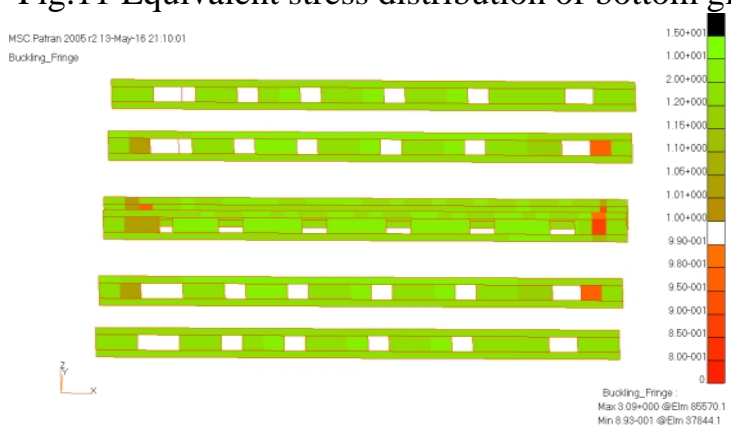

Fig.13 Buckling strength of bottom girder 


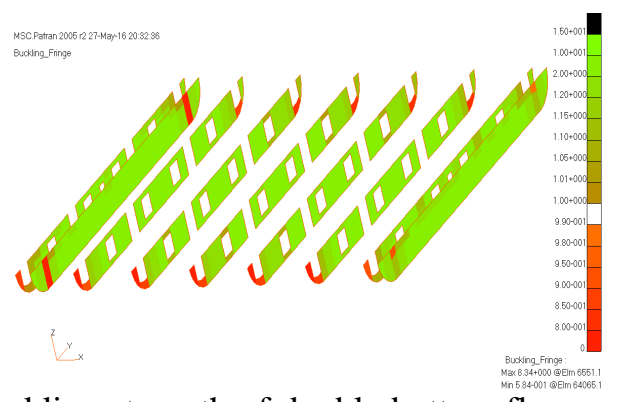

Fig.14 Buckling strength of double bottom floor

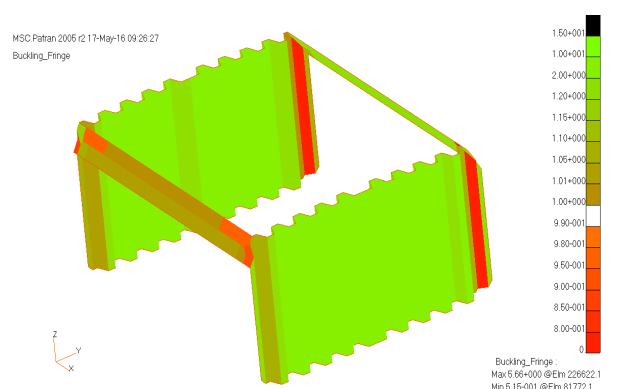

Fig.15 Buckling strength of transverse bulkhead and sloping plating of top side tank

\section{Calculating results and structural strength}

It is revealed through calculating results that the structural yield and buckling strength of deck, inner bottom, inner shell plating, bottom girder, sloping plating of top side tank, transverse bulkhead and double bottom floor dissatisfy the requirement. Strengthening scheme shall be proposed about the structures dissatisfied the requirement of strength. The results strengthened are shown in Table8. The distribution of structural yield and buckling strength is shown in Figure 16-21.

(1) The thickness of deck, inner bottom and sloping plating of top side tank is strengthened from $12 \mathrm{~mm}$ to $15 \mathrm{~mm}$, which the sloping plating of top side tank are made of AH32 high strength steel.

(2) Bottom girder from Fr65 to Fr73 and Fr89 to Fr97 are replaced in AH32 high strength steel.

(3) High steel AH36 is used in area of non-watertight floor from $4270 \mathrm{~mm}-5690 \mathrm{~mm}$ distant from mid-ship and the open hole area of non-watertight floor from $6030 \mathrm{~mm}-8400 \mathrm{~mm}$ distant from mid-ship; The thickness of non-watertight floor in bilge shall strengthen from $10 \mathrm{~mm}$ to $15 \mathrm{~mm}$ and high strength steel AH36 will be used.

(4) The ball flat steel whose size is FB100-15 shall be added in the position 6998mm distant from mid-sip in transverse bulkhead with slot typ. In addition, the thickness of bulkhead distant $7123 \mathrm{~mm}-7400 \mathrm{~mm}$ from mid-ship shall increase to $16 \mathrm{~mm}$, of which the high strength steel AH36 shall be used.

Tab.8 Comparison of the yield and buckling results before and after the structure strengthening

\begin{tabular}{|c|c|c|c|c|c|c|}
\hline Hull structure & $\begin{array}{l}\text { Equivalent } \\
\text { stress of } \\
\text { original } \\
\text { structure } \\
\left(\mathrm{N} / \mathrm{mm}^{2}\right)\end{array}$ & $\begin{array}{l}\text { Equivalent } \\
\text { stress of } \\
\text { structure } \\
\text { strengthened } \\
\left(\mathrm{N} / \mathrm{mm}^{2}\right)\end{array}$ & $\begin{array}{l}\text { Allowable } \\
\text { equivalent } \\
\text { stress } \\
\left(\mathrm{N} / \mathrm{mm}^{2}\right)\end{array}$ & $\begin{array}{l}\text { Buckling safety } \\
\text { equivalent value } \\
\text { of original } \\
\text { structure }\end{array}$ & $\begin{array}{l}\text { Buckling safety } \\
\text { equivalent value } \\
\text { of structures } \\
\text { strengthened }\end{array}$ & Criterion \\
\hline Deck & 243 & 209 & 220 & 0.444 & 1.1 & 0.8 \\
\hline Inner bottom plating & 235 & 208 & 220 & 0.516 & 0.859 & 0.8 \\
\hline Inner shell plating & 237 & 216 & 220 & 0.886 & 0.859 & 0.8 \\
\hline Bottom girder & 306 & $205 / 296$ & $235 / 301$ & 0.893 & 1.09 & 1 \\
\hline Double bottom floor & 270 & $170 / 231$ & $175 / 224$ & 0.584 & 0.898 & 0.8 \\
\hline Transverse bulkhead & 206 & $157 / 242$ & $175 / 243$ & 0.515 & 0.823 & 0.8 \\
\hline $\begin{array}{l}\text { Sloping plating of } \\
\text { top side tank }\end{array}$ & 270 & 234 & 250 & 0.551 & 1.12 & 0.8 \\
\hline 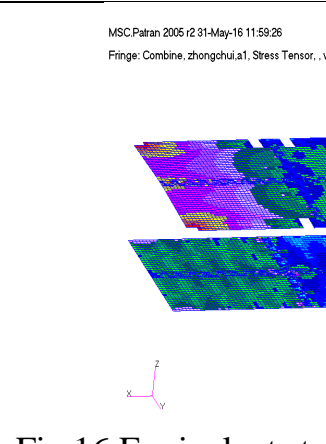 & & 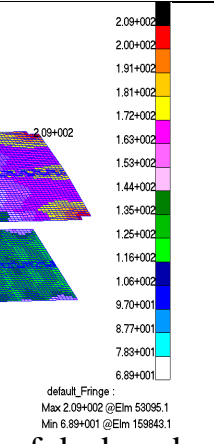 & & 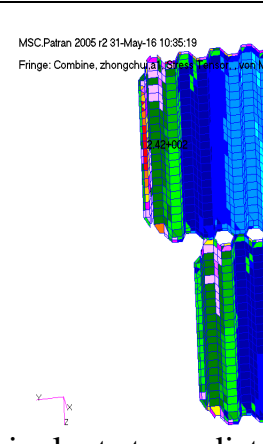 & & 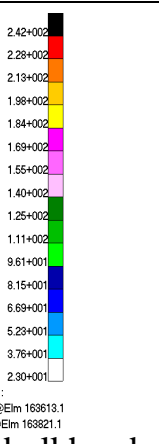 \\
\hline
\end{tabular}

Fig.16 Equivalent stress distribution of deck and

Fig.17 Equivalent stress distribution of transverse bulkhead inner bottom 


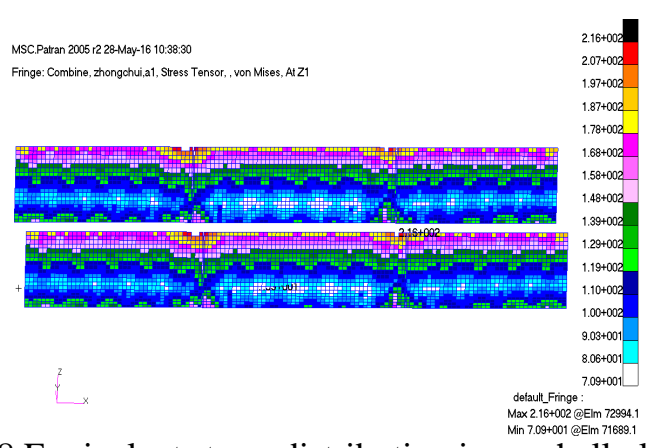

Fig18 Equivalent stress distribution inner shell plating

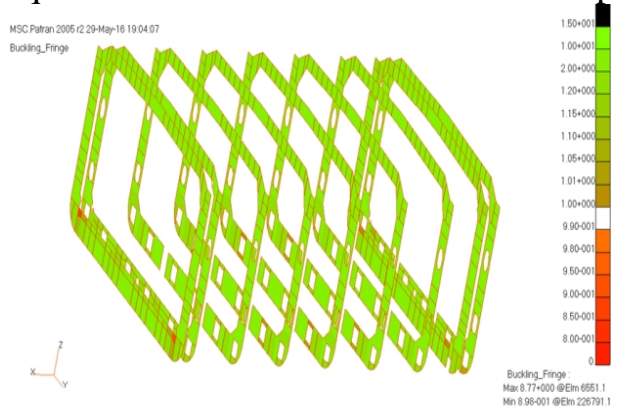

Fig.20Buckling strength of double bottom floor and transverse web frame

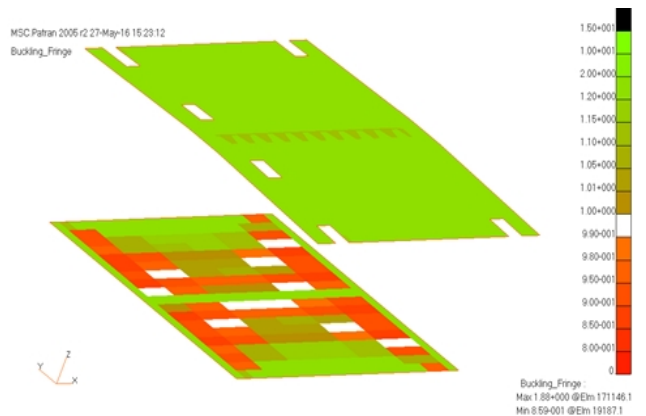

Fig.19 Buckling strength of deck and inner bottom

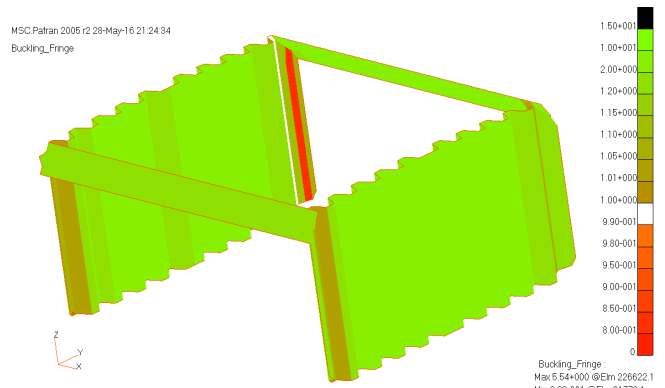

Fig.21 Buckling strength of transverse bulkhead and sloping plating of top side tank

\section{Conclusions}

By means of the two kinds of calculation upon asphalt carrier consider with and without temperature field, the finite element calculating results are shown in Table 4.1.1 that the yield strength and buckling strength of each hull structure satisfy the requirement of the specification when the influence of temperature on hull structure is ignored; the yield strength and buckling strength of some hull structures dissatisfy the requirement of the specification when the influence of temperature on hull structure is considered.

Besides, Different temperature load may have different degree of influence on different structures. In terms of yield strength, the influence of temperature on side plate, bottom shell plate, deck, sloping plating of hopper tank and side plating of lower is the least, which average equivalent stress increases $40 \mathrm{~N} / \mathrm{mm} 2$. The influence of temperature load on inner bottom plate, inner shell plate, horizontal girder in double hulls, bottom girder, double bottom floor, transverse bulkhead and sloping plating of top side tank is the greatest, which average equivalent stress increases $118 \mathrm{~N} / \mathrm{mm} 2$. In terms of buckling strength, the influence of temperature load on bottom shell plate and side shell plate is almost ignored, which temperature load has little influence on inner bottom plate, horizontal girder in double hulls, double bottom floor and the influence is the greatest in transverse bulkhead.

In terms of structures strengthening, structures dissatisfied the requirement of yield and buckling strength are replaced by high strength steel, added other structures to strengthen or increase the thickness of plates. The detailed strengthen patterns and results have been obtained in paper. In addition, it is proposed that the heat conduction coefficient of rock wool shall reduce by adding the thickness of rock wool layer or replacing the material of rock wool layer.

\section{Acknowledgements}

We acknowledge the support of International S\&T Cooperation Program of China (Grant No.2012DFR80170), National Natural Science Foundational of China (Grant No.51279182) and Zhejiang provincial Natural Science Foundation of China (Grant No.LQ13E090002). 


\section{References}

[1] FENG Guo-zeng, SUN Shao-zhe. Design of Cascade-heating System for 6000DWT Asphalt Carrier [J]. ship Engineering. Feb. 2015:P.38.

[2] LI Bing. FE Analysis of the Asphalt Carrier Including the Temperature Stress[J]. Mechanical and Electrical Equipment. July 2012:P.50.

[3] DU Hua-ming. The Temperature Field and Stress Finite Element Analysis of Asphalt Shin with Different Forms of Bulkhead [D]. Wuhan University of Technology. October 2008:P.1-3.

[4] HUANG Ni. Direct Strength Analysis Of Ship's structure Taking Account of Thermo Stress[D]. Wuhan University of Technology. October 2007:P.2.

[5] LI Jun-lai. Thermal Stress Analysis of the Asphalt Carrier's Cargo Structure based on the Thermal Deformation[J]. Journal of Zhejiang Ocean University(Natural Science). Mar. 2014:P.180.

[6] LI Jun-lai. Strength Analysis of the Asphalt Carrier Cargo Component Based on the Temperature Stress Field Thermal Deformation[J]. Journal of Zhejiang Ocean University(Natural Science). Mar. 2008:P.5.

[7] LI Min. Analysis of temperature field and Stress for Independent C-type Tank of the Small and Medium LNG Carriers [D]. South China University of Technology. May 2013:9.

[8] China Classification Society. Rules for Classification of Sea-Going Ships[S].July 2015:P.175-178,284-287.

[9] Xu YI-min. Research on Direct Strength Calculation of Structure and Fatigue of Ship[D]. Jiangnan University. Jun 2014:P.32-35 